\title{
Novel effect of estrogen on RANK and $c$-fms expression in RAW 264.7 cells
}

\author{
NADIA GALAL ${ }^{1,2,3}$, WALEED R. EL-BEIALY ${ }^{1,2,3}$, YOSHIAKI DEYAMA ${ }^{2}$, \\ YOSHITAKA YOSHIMURA $^{2}$, KUNIAKI SUZUKI $^{2}$ and YASUNORI TOTSUKA ${ }^{1}$
}

\begin{abstract}
Departments of ${ }^{1}$ Oral and Maxillofacial Surgery, ${ }^{2}$ Molecular Cell Pharmacology, Hokkaido University Graduate School of Dental Medicine, Hokkaido, Japan; ${ }^{3}$ Department of Oral and Maxillofacial Surgery, Faculty of Oral and Dental Medicine, Cairo University, Cairo, Egypt
\end{abstract}

Received February 20, 2007; Accepted March 26, 2007

\begin{abstract}
Temporomandibular disorder (TMD), a progressive disease entity, and osteoarthrosis preferentially affect females, denoting a possible role of estrogen. Using RAW 264.7 cells, the expression of estrogen receptors (ERs) $\alpha$ and $\beta$ and the consequent effect of estrogen was investigated. We present the novel detection of ER $\beta$ expression in RAW 264.7 cells. Furthermore, we innovatively demonstrated the increase in expression of both ER $\alpha$ and $\beta$, as well as RANK and $c$-fms, with estrogen treatment. However, a decrease in expression of $c$-fms, RANK and ER $\beta$, and nearly no change in the expression of ER $\alpha$ were experienced upon further increase in estrogen concentrations. These findings lead us to hypothesize a new mechanism of inflammation in TMD.
\end{abstract}

\section{Introduction}

Estrogen, a representative steroid hormone, is known to regulate diverse physiological processes of target tissues (1) in both sexes. The biological activities of estrogen are initiated by binding to the specific receptor proteins, namely the estrogen receptors (ERs) (2). Two main isoforms of ER have been identified to date, ER $\alpha$ and ER $\beta$. The latest discovery of ER $\beta$ was unexpected during a search for novel androgen receptors in a rat prostate cDNA library (3). Immunocytochemistry using specific antibodies revealed that ER $\alpha$ was widely distributed in various tissues, whereas the definitive distribution of ER $\beta$ protein remained unclear (2).

Correspondence to: Dr Yoshiaki Deyama, Department of Molecular Cell Pharmacology, Hokkaido University Graduate School of Dental Medicine, Kita-ku, Kita 13 Nishi 7, Sapporo, Hokkaido, Japan

E-mail: dey@den.hokudai.ac.jp

Key words: estrogen, estrogen receptors, c-fms, RANK, RAW 264.7 cells, temporomandibular disorder, osteoarthrosis, bone resorption, inflammation
The nuclear receptor (NR) genes are a large family of genes, coding for similar proteins, whose functions are to accept incoming signals from various messenger molecules. NR genes are typically found on the nuclear membrane or less frequently, free in the cell cytoplasm (4). The steroid nuclear receptors are a sub-family of the NR super-family, mediating the cellular effects of steroid hormones. Estrogen is a key regulator of skeletal mass. The effects of estrogen on osteoblasts include both direct effects, resulting in increased bone formation, and indirect effects, via an osteoblastmediated interaction with pre-osteoclasts and osteoclasts, resulting in decreased bone resorption (5). The effects of estrogen on skeletal cells are complex, and the mechanism(s) of action are controversial (6).

RANKL (receptor activator of $N_{\kappa} B$ ligand) is a membrane-bound ligand expressed on osteoblasts. Binding of RANKL to its receptor RANK which is expressed on osteoclast precursors and mature osteoclasts, induces osteoclastogenesis and activation of mature osteoclasts (7-11). RANK is a member of the TNF-R super-family, expressed as a transmembrane heterotrimer on the surface of haematopoietic osteoclast progenitors, mature osteoclasts, chondrocytes, and mammary gland epithelial cells (12-16). Estrogen has been shown to suppress RANKL-induced osteoclast differentiation in vitro (17). Macrophage colony stimulating factor-1 (M-CSF, CSF-1) is essential for osteoclastogenesis, as demonstrated by osteopetrotic defects in both M-CSF and M-CSF receptor $(c-f m s)$ knockout mice $(18,19)$, and for the survival of mature osteoclasts (20). Importantly, M-CSF stimulates the spreading and migration of osteoclasts together with the attenuation of bone resorption (21). The $c$-fms gene encodes the receptor for macrophage colony-stimulating factor-1. This gene is expressed selectively in the macrophage cell lineage (22).

The synovial membrane in the temporomandibular joint (TMJ) has an important role in joint movement because of the involvement of the synovial lining cells in the synovial fluid metabolism, which affects smooth jaw movement. Many ultrastructural investigations have pointed out that the synovial membrane consists of two kinds of synovial lining cells; macrophage-like type A and fibroblastic type B cells $(23,24)$. Taken together, these findings lead us to hypothesize that the 
TMJ is a target tissue for estrogen. However, little information is available regarding the localization of ER $\alpha$ and $\beta$ in the TMJ.

Available precedents suggest that the effects of estrogen on osteoclast progenitors and osteoclast differentiation may be more important than the effects on formed osteoclasts (25-27). Our study targeted the effects of estrogen on osteoclast precursors represented by the murine monocytic line RAW 264.7. We detected the presence of ERs in RAW 264.7 cells and examined the effects of estrogen on RAW 264.7 cells regarding the $c$-fms and RANK receptors.

\section{Materials and methods}

Cell culture. RAW 264.7 cells were first cultured in complete medium $\alpha$-MEM supplemented with $66.7 \% \mu \mathrm{g} / \mathrm{ml}$ kanamycin and $10 \%$ fetal calf serum (FCS). Cells were incubated in a humidified $5 \% \mathrm{CO}_{2}$ atmosphere at $37^{\circ} \mathrm{C}$.

Exogenous $17 \beta$-estradiol treatment. At confluence, different concentrations $\left(10^{-8}, 10^{-9}, 10^{-10}\right.$ and $\left.10^{-11} \mathrm{M}\right)$ of 173 -estradiol (in ethanol, Sigma-Aldrich, St. Louis, MO) were added to the medium for periods of $1,3,6,12$ and $24 \mathrm{~h}$, while controls were treated with an equivalent volume of ethanol (estrogen vehicle). Exposure was terminated by rapid aspiration of the media.

Reverse transcription $(R T)$-polymerase chain reaction $(P C R)$. Total RNA was isolated using guanidinium thiocyanate-phenol-chloroform extraction (TRIzol, Invitrogen Corp., Carlsbad, CA). The RNA pellets were dissolved in distilled water and quantified using a Nano-Drop spectrophotometer ND-1000 (NanoDrop Tech., Inc., Wilmington, DE). Total RNA was reverse transcribed using oligo(dt) primers and reverse transcriptase (Toyobo, Tokyo, Japan) according to the manufacturer's protocol.

PCR amplification. For expression of ER $\alpha$ and $\beta$, a mixture of $0.16 \mathrm{mM}$ dNTP, $0.4 \mu \mathrm{M}$ primer $\mathrm{F}, 0.4 \mu \mathrm{M}$ primer $\mathrm{R}$, and KOD-Dash (Toyobo) was prepared. At first, gene-specific primers for human glyceraldehyde-3-phosphate dehydrogenase (G3PDH) were used to test cDNA quality. Amplification was performed as follows: 35 cycles at $94^{\circ} \mathrm{C}$ for $30 \mathrm{sec}$, annealing at $60^{\circ} \mathrm{C}$ for $2 \mathrm{sec}$, and $72^{\circ} \mathrm{C}$ for $30 \mathrm{sec}$. The first cycle was conducted at $94^{\circ} \mathrm{C}$ for $10 \mathrm{~min}$ and the final cycle at $72^{\circ} \mathrm{C}$ for $10 \mathrm{~min}$.

For $c$-fms and RANK a mixture of $0.16 \mathrm{mM}$ dNTP mix, $1 \mu \mathrm{l}$ of each sense and antisense primer $(0.4 \mu \mathrm{M})$, and Tag gold was used. Gene-specific primers for B-2 microglobulin were used to test cDNA quality and equalization. Amplification was performed as follows: 30 cycles with the first cycle conducted at $95^{\circ} \mathrm{C}$ for $11 \mathrm{~min}$ and at $95^{\circ} \mathrm{C}$ for $1 \mathrm{~min}$, with annealing at $58^{\circ} \mathrm{C}$ and $72^{\circ} \mathrm{C}$ for $1 \mathrm{~min}$, and with the last cycle at $72^{\circ} \mathrm{C}$ for $10 \mathrm{~min}$. The sequences of the used primers are as shown in Table I.

Following PCR, the reaction products were resolved on $2 \%$ agarose gel by electrophoresis. Gel was stained with ethidium bromide to visualize the PCR products. The levels of expression of ER $\alpha$, ER $\beta$, RANK and $c$-fms were analyzed with Image J 1.37 v (Rasband, W.S., ImageJ, US National Institute of Health, Bethesda, MD, USA, 1997-2006) and normalized with $3-2$ microglobulin mRNA expression.
Table I. The sequences of the used primers.

\begin{tabular}{ll}
\hline Primer & \multicolumn{1}{c}{ Sequence } \\
\hline ER $\alpha$ & \\
Forward & CAAGGAGGGAGTGCGTCTGG \\
Reverse & CATCTAGGACCAGGTCCTCAGC \\
ER $\beta$ & \\
Forward & TCTGCAGTGATTATGCATCTGGG \\
Reverse & CTTCGTGAGGGACATCATCATGG \\
RANK & \\
Forward & CCA GGG GAC AAC GGA ATC A \\
Reverse & GGC CGG TCC GTG TAC TCA TC \\
$c$-fms & \\
Forward & GCG ATG TGT GAG CAA TGG CAG T \\
Reverse & AGA CCG TTT TGC GTA AGA CCT G \\
G3PDH & \\
Forward & GTCTACATGTTCCAGTATGACTCC \\
Reverse & AGCCTTCTCCATGGTGGTGAAGAC \\
B-2 microglobulin & \\
Forward & GCT ATC CAG AAA ACC CCT CAA \\
Reverse & CATGTCTCGATCCCAGTAGACGGT \\
\hline
\end{tabular}

Western blotting. For protein extraction, at confluence, media were aspirated, cells were washed with Dulbecco's phosphate-buffered saline without calcium and magnesium (1X PBS), and lysis buffer was added (10 mM HEPES$\mathrm{KOH}$ at $\mathrm{pH} 7.5,100 \mathrm{mM} \mathrm{KCl}$, and $0.1 \% \mathrm{NP}-40)$. Cells were lysed thoroughly and dislodged from the plate by repetitive pipetting. Protein concentrations were assessed by the BioRad protein assay kit. Controls for both $\alpha$ and $\beta$ were used (MCF7 whole cell lysate for $\alpha$ and NIH/3T3 whole cell lysate for $B$, Santa Cruz Biotechnology, Inc., CA). Samples were separated on $10 \%$ polyacrylamide gels and transferred onto polyvinylidene difluoride membranes. Membranes were blocked for $1 \mathrm{~h}$ in 5\% skim milk followed by 3 washings with TBS containing $0.1 \%$ Tween buffer and were placed in a primary antibody [1:200 ER $\alpha(\mathrm{H}-184)$ rabbit polyclonal IgG and 1:500 ER $\beta$ rabbit polyclonal IgG, Santa Cruz Biotechnology, Inc.] overnight at $4^{\circ} \mathrm{C}$ on a shaker, followed by 3 washings with TBST and placed in a secondary antibody (1:2500 HRP-goat anti-rabbit IgG, Zymed, San Francisco, CA) for $1 \mathrm{~h}$ at room temperature on a shaker. After 3 washings for $15 \mathrm{~min}$, the membranes were incubated in Western Lightning ${ }^{\circledR}$ Chemiluminescence Reagent Plus (Perkin Elmer, Boston, MA). Medical X-ray films were used to visualize the chemiluminescence.

\section{Results}

Expression of estrogen receptors in RAW 264.7 cells. ERs are central to the study, so we examined the expression of ER $\alpha$ and $\beta$ in RAW 264.7 cells. Using PCR (a 35-cycle amplification) both ER $\alpha$ and $\beta$ were expressed as a specific single band in RAW 264.7 cells (Fig. 1). On the other hand, Western 


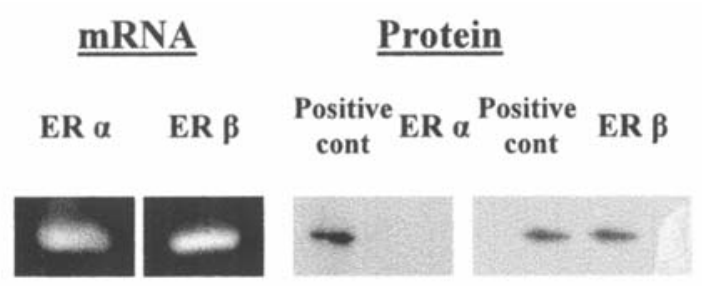

Figure 1. (Left panels) Estrogen receptors ER $\alpha$ and $\beta$ RNA expression in macrophage cells. RAW 264.7 cells were analyzed by RT-PCR for the presence of the mRNA encoding ER $\alpha$ and $B$. Cells were cultured under standard growth conditions, and RNA was extracted and retrotranscribed using the reverse transcriptase enzyme. ER $\alpha$ and $\beta$ were expressed as specific single bands. (Right panels) Western blot analysis for ERs. The whole cell lysates from RAW 264.7 cells were analyzed for the expression of ER $\alpha$ and $B$. The positive controls were MCF7 whole cell lysate for $\alpha$ and NIH/3T3 whole cell lysate for B. Cont, control.

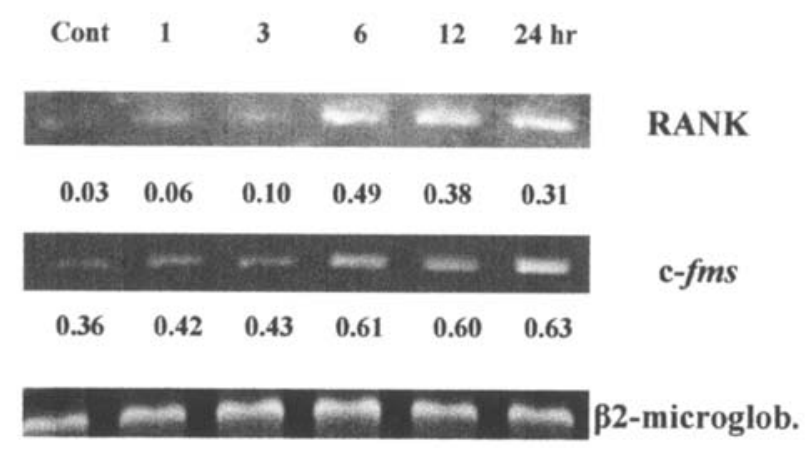

Figure 2. The effect of 17ß-estradiol on RANK and $c$-fms mRNA expression in RAW 264.7 cells. Cells were incubated with $10^{-11} \mathrm{M} 173$-estradiol for periods of 1, 3, 6, 12 and $24 \mathrm{~h}$. RNA was isolated and RT-PCR was performed. There was a gradual increase in expression of both RANK and c-fms after $1 \mathrm{~h}$, which then obviously increased at $6 \mathrm{~h}$. Cont, control.

blotting confirmed the expression of ER $\beta$, while no adequate signal was detected for ER $\alpha$ (Fig. 1).

A band corresponding to the expected size of G3PDH was detected (data not shown).

Effect of estrogen on RAW 264.7 cells. At confluence, following the addition of $10^{-11} \mathrm{M} 173$-estradiol (in ethanol) to the medium for periods of $1,3,6,12$ and $24 \mathrm{~h}$, the effect of estrogen on RANK and $c$-fms in RAW 264.7 cells was investigated. PCR amplification for 30 cycles revealed that estrogen directly affected expression of RANK and c-fms. cDNA quality and equality were checked by $B-2$ microglobulin. For both RANK and $c$-fms there was increased expression after $1 \mathrm{~h}$ following the addition of estrogen. There was a time-dependent increase in the expression of RANK and $c$-fms after application of estrogen with maximum expression at $6 \mathrm{~h}$ (Fig. 2).

Effect of estrogen on ER receptors. The capacity of estrogen to increase expression of RANK and $c$-fms and the detection of ERs in RAW cells suggested mediation by ERs (ER $\alpha$ or ER B) so we studied the effect of estrogen on ERs. The expression of both ER $\alpha$ and $\beta$ after the addition of $10^{-11} \mathrm{M}$

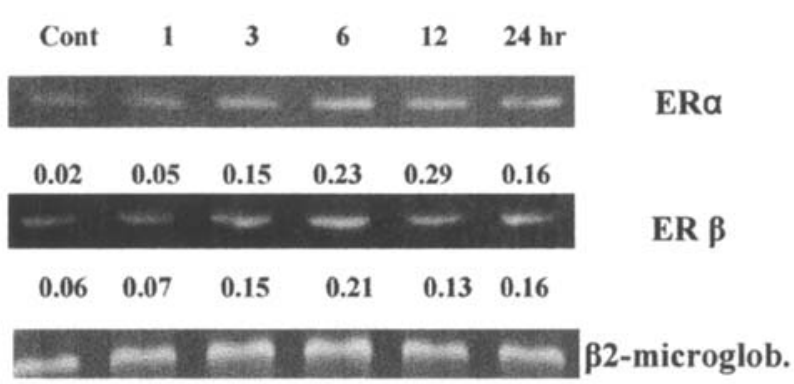

Figure 3. The effects of 17ß-estradiol on ER $\alpha$ and $\beta$ mRNA expression in RAW 264.7 cells. Cells were incubated with $10^{-11} \mathrm{M} 173$-estradiol for periods of $1,3,6,12$ and $24 \mathrm{~h}$. RNA was isolated, and RT-PCR was performed. A gradual increase in expression of ER $\alpha$ and $\beta$ with time was observed, with the obvious effect taking place after $6 \mathrm{~h}$. Cont, control.

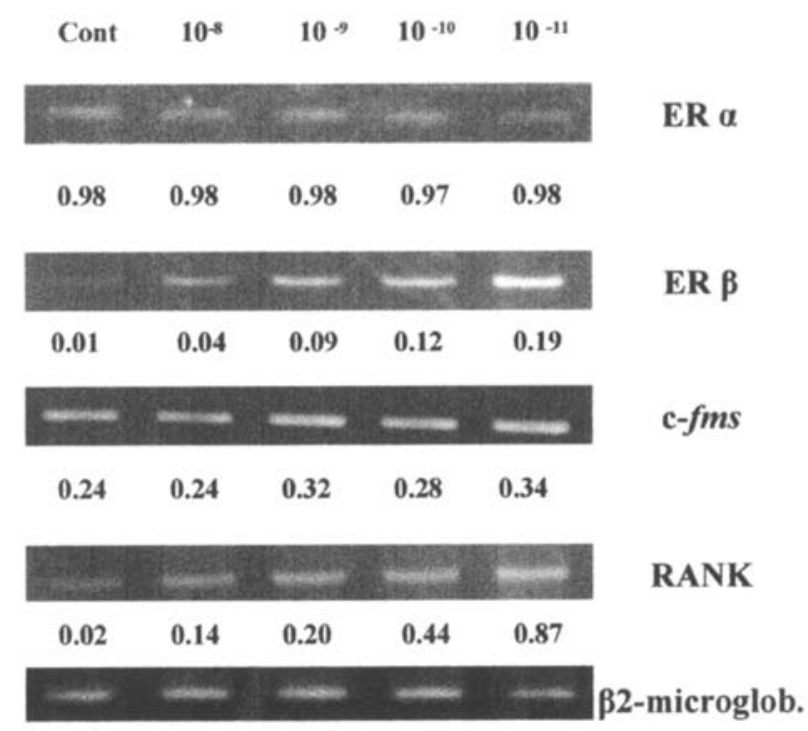

Figure 4. The effect of different concentrations of 17ß-estradiol on the expression of $c$-fms, RANK and ERs. PCR amplification was conducted to study the effect of different concentrations on the expression of RANK, $c$-fms and ERs. There was nearly no change in the expression of ER $\alpha$ at different concentrations of 17ß-estradiol, while there was a gradual decrease in expression of RANK and $c$-fms with increasing estrogen concentration, with a similar decrease in ER $\beta$ expression. Cont, control.

17ß-estradiol for periods of $1,3,6,12$ and $24 \mathrm{~h}$ was studied. PCR amplification of 30 cycles was conducted for both ERs. There was a gradual increase in expression of both ER $\alpha$ and $\beta$ with time, with the obvious effect taking place after $6 \mathrm{~h}$ and a slight decrease in expression of ER $\alpha$ at $24 \mathrm{~h}$ (Fig. 3).

Concentration dependency of estrogen. At confluence, different concentrations $\left(10^{-8}, 10^{-9}, 10^{-10}\right.$ and $\left.10^{-11} \mathrm{M}\right)$ of $17 ß-$ estradiol (in ethanol) were added to the medium for a period of $6 \mathrm{~h}$. PCR amplification was performed to study the effect of different concentrations on the expression of RANK, $c$-fms and ERs. There was nearly no change in the expression of ER $\alpha$ at concentrations $10^{-11}$ to $10^{-8} \mathrm{M}$, while there was a gradual decrease in expression of RANK and $c$-fms with increase in estrogen concentration, with the same decrease occurring in ER B expression (Fig. 4). 


\section{Discussion}

As direct targets for pharmaceuticals, estrogen receptors represent a promising biological system for the discovery of potent, selective and specific drugs to control the evolution of several disorders (28). Macrophage cell lines expressing endogenous estrogen receptors represent valuable tools in the study of hormonal activity on inflammatory cells and to discern the mechanism of action of hormone and hormonerelated drugs.

Previous studies have failed to detect ER $\beta$ in RAW 264.7 cells (29), but in this study we present its novel detection in RAW 264.7 cells. We have also demonstrated the expression of ER $\alpha$ receptor. Results from our present study demonstrated increased expression of both ER $\alpha$ and $\beta$ in RAW 264.7 cells with time after application of $10^{-11} \mathrm{M}$ estrogen. Since the synovial membrane consists of two kinds of synovial lining cells; macrophage-like type A and fibroblastic type B cells $(23,24)$, this proves that type A synovial lining cells possess estrogen receptors through which estrogen can exert its effect on the joint.

Macrophages are the patrolling cells of innate immunity, involved in the recognition of foreign pathogens, in the elimination of toxic molecules and in the reconstitution of tissue integrity. Macrophage cells orchestrate these diverse pathways by producing several different mediators, such as nitric oxide (NO), cytokines including interleukin 13 (IL-1ß) and tumor necrosis factor- $\alpha(\mathrm{TNF}-\alpha)$, and matrix degrading enzymes such as metalloprotease-9 (MMP-9). The production of these molecules, although beneficial for killing bacteria and further activating the immune system, exerts damaging effects on the surrounding tissue when chronically or erroneously stimulated (30).

The differentiation of macrophages from bone marrow progenitors requires the coordinated expression of many genes needed for mature cell function. This process is controlled by the lineage-specific growth factor macrophage colonystimulating factor-1 (CSF-1), which acts by binding to cell surface receptors (CSF-1Rs) encoded by the $c$-fms protooncogene (31). Our results revealed an increased expression of $c$-fms following estrogen treatment, based on which we hypothesized a resultant increase in macrophage colonization via $c$-fms. Such a hypothesis, in an attempt to scientifically explain a female tendency to TMD, might interpret the increase in macrophage colonization to be a contributing factor in the increased inflammation and tendency of females to suffer more from temporomandibular joint disorders in the presence of external exacerbating factors.

Until recently, inflammatory cytokines, such as IL-1, IL-6, IL-11, and TNF, were implicated as important mediators of bone lysis (32). Recent findings, however, indicate that osteoclasts have a substantial role in bone destruction, and that RANKL might be the central mediator of osteoclast development.

In the presence of CSF-1 sufficient to maintain cell growth and survival, RANKL, via its tumor necrosis factor family receptor RANK, is sufficient to induce complete osteoclastic differentiation from hematopoietic precursors (33). It has been established that estrogen withdrawal causes rapid skeletal degradation, an effect that certainly involves other cells, including osteoblasts, but which has been hypothesized to involve direct effects on osteoclast formation (34).

Previous studies reported that estrogen does not affect RANK (17). However, our current study substantiates a direct effect of estrogen on RANK in osteoclast precursors where addition of $17 \beta$-estradiol caused a direct increase in RANK expression. We hypothesize that the increase in expression of RANK is a reaction of the RAW 264.7 cells (osteoclast precursors) to compensate for the decreased level of RANKL caused by estrogen (17).

Estrogens have been demonstrated to act via ER B in tissues of the central nervous system, cardiovascular system, immune system, urogenital tract, gastrointestinal tract, kidney and lungs (35). We demonstrated that $10^{-11} \mathrm{M}$ of estrogen is the optimum concentration for estrogen effects via ER $\beta$, and that higher concentrations caused a decreased expression of ER $ß$. Higher estrogen concentrations beyond optimal also caused a contemporaneous decrease in RANK and $c$-fms while having no effect on the expression of ER $\alpha$, denoting a coexisting relation between estrogen and the ER $\beta$ receptor.

In conclusion, we report that type A synovial lining cells express ERs $\alpha$ and $\beta$ which are increased by estrogen treatment and we hypothesized an increase in macrophage colonization via the reported increase in $c$-fms. Furthermore, we demonstrated that osteoclast precursors are direct targets of estrogenic effects. These results may provide an interpretation for the increased inflammation and tendency of females to suffer from temporomandibular joint disorders; hence, providing novel targets for both prevention and therapy.

\section{References}

1. Galand P, Leroy F and Chretien J: Effect of estradiol on cell proliferation and histological changes in the uterus and vagina of mice. J Endocrinol 49: 243-252, 1971.

2. Pavao M and Traish AM: Estrogen receptor antibodies: specificity and utility in detection, localization and analyses of estrogen receptor $\alpha$ and $\beta$. Steroids 66: 1-16, 2001.

3. Kuiper GG, Enmark E, Pelto Huikko M, Nilsson S and Gustafsson JA: Cloning of a novel estrogen receptor expressed in rat prostate and ovary. Proc Natl Acad Sci USA 93: 5925-5930, 1996

4. Fryer CJ, Kinyamu HK, Rogatsky I, Garabedian MJ and Archer TK: Selective activation of the glucocorticoid receptor by steroid antagonists in human breast cancer and osteosarcoma cells. J Biol Chem 275: 17771-17777, 2000.

5. Lindberg MK, Erlandsson M, Alatalo SL, et al: Estrogen receptor $\alpha$, but not estrogen receptor $\beta$, is involved in the regulation of the OPG/RANKL (osteoprotegerin/receptor activator of NF- $\mathrm{KB}$ ligand) ratio and serum interleukin-6 in male mice. J Endocrinol 171: 425-433, 2001.

6. Rickard DJ, Subramaniam M and Spelsberg TC: Expression of the human oestrogen receptor-alpha gene is regulated by promoter F in MG-63 osteoblastic cells. J Cell Biochem 32-33 123-132, 1999.

7. Lacey DL, Timms E, Tan HL, et al: Osteoprotegerin ligand is a cytokine that regulates osteoclast differentiation and activation. Cell 93: 165-176, 1998

8. Kong YY, Yoshida H, Sarosi I, et al: OPGL is a key regulator of osteoclastogenesis, lymphocyte development and lymphnode organogenesis. Nature 397: 315-323, 1999.

9. Simonet WS, Lacey DL, Dunstan CR, et al: Osteoprotegerin a novel secreted protein involved in the regulation of bone density. Cell 89: 309-319, 1997.

10. Mitani M, Miura Y and Saura R: Estrogen specifically stimulates expression and production of osteoprotegerin from rheumatoid synovial fibroblasts. Int J Mol Med 15: 827-832, 2005 . 
11. Wong BR, Rho J, Arron J, et al: TRANCE is a novel ligand of the tumor necrosis factor receptor family that activates C-Jun Nterminal kinase in T cells. J Biol Chem 272: 25190-25194, 1997.

12. Fata JE, Kong YY, Li J, et al: The osteoclast differentiation factor osteoprotegerin-ligand is essential for mammary gland development. Cell 103: 41-50, 2000.

13. Lum L, Wong BR, Josien R, et al: Evidence for a role of a tumor necrosis factor-alpha (TNF-alpha) converting enzymelike protease in shedding of TRANCE, a TNF family member involved in osteoclastogenesis and dendritic cell survival. J Biol Chem 274: 13613-13618, 1999.

14. Nakashima T, Kobayashi Y, Yamasaki S, et al: Protein expression and functional difference of membrane-bound and soluble receptor activator of NF-kappaB ligand: modulation of the expression by osteotropic factors and cytokines. Biochem Biophys Res Commun 275: 768-775, 2000

15. Kartsogiannis V, Zhou H, Horwood NJ, et al: Localization of RANKL (receptor activator of NFKB ligand) mRNA and protein in skeletal and extraskeletal tissues. Bone 25: 525-534, 1999.

16. Lagasse E and Weissman IL: Enforced expression of Bcl-2 in monocytes rescues macrophages and partially reverses osteopetrosis in op/op mice. Cell 89: 1021-1031, 1997.

17. Shevde NK, Bendixen AC, Dienger KM and Pike JW: Estrogens suppress RANK ligand-induced osteoclast differentiation via a stromal cell independent mechanism involving c-Jun repression. Proc Natl Acad Sci USA 97: 7829-7834, 2000.

18. Suda T, Udagawa $\mathrm{N}$ and Takahashi N: Osteoclast generation. In: Principles of Bone Biology; Cells of Bone. Bilezikian JP, Raisz LG and Rodan GA (eds). Academic Press, San Diego, pp87-102, 1996.

19. Dai XM, Ryan GR, Hapel AJ, et al: Targeted disruption of the mouse colony stimulating factor 1 receptor gene results in osteopetrosis, mononuclear phagocyte deficiency, increased primitive progenitor cell frequencies, and reproductive defects. Blood 99: 111-120, 2002.

20. Wiktor-Jedrzejczak W, Ratajczak MZ, Ptasznik A, Sell KW, Ahmed-Ansari A and Ostertag W: CSF-1 deficiency in the op/op mouse has differential effects on macrophage populations and differentiation stages. Exp Hematol 20: 1004-1010, 1992.

21. Felix R, Hofstetter W, Wetterwald A, Cecchini MG and Fleisch H: Role of colony-stimulating factor- 1 in bone metabolism. J Cell Biochem 55: 340-349, 1994.

22. Fuller K, Owens JM, Wilson A, Moss R and Chambers TJ: Macrophage colony-stimulating factor stimulates survival and chemotactic behavior in isolated osteoclasts. J Exp Med 178: 1733-1744, 1993.
23. Khalkhali-Ellis Z, Seftor EA, Nieva DR, et al: Estrogen and progesterone regulation of human fibroblast-like synoviocyte function in vitro: implications in rheumatoid arthritis. J Rheumatol 27: 1622-1631, 2000.

24. Barland P, Novikoff $\mathrm{AB}$ and Hamerman D: Electron microscopy of the human synovial membrane. J Cell Biol 14: 207-220, 1962

25. Graabak PM: Characteristics of the two types of synoviocytes in rat synovial membrane. Lab Invest 50: 690-702, 1984.

26. Shevde NK and Pike JW: Estrogen modulates the recruitment of myelopoietic cell progenitors in rat through a stromal cellindependent mechanism involving apoptosis. Blood 87: 2683-2692, 1996.

27. Fiorelli G, Gori F, Petilli M, et al: Functional estrogen receptors in a human preosteoclastic cell line. Proc Natl Acad Sci USA 92: 2672-2676, 1995.

28. Cao 1, Bu R, Oakley JI, Kalla SE and Blair HC: Estrogen receptor-beta modulates synthesis of bone matrix proteins in human osteoblast-like MG63 cells. J Cell Biochem 89: 152-164, 2003.

29. Emery GJ, Ohlstein EH and Jaye M: Therapeutic modulation of transcriptional factor activity. Trends Pharmacol Sci 22: 233-240, 2001.

30. Palacios VG, Robinson LJ, Borysenko CW, Lehmann T, Kalla SE and Blair HC: Negative regulation of RANKL-induced osteoclastic differentiation in RAW264.7 cells by estrogen and phytoestrogens. J Biol Chem 14: 13720-13727, 2005.

31. Kreutzberg GW: Microglia A sensor for pathological events in CNS. Trends Pharmacol Sci 8: 312-318, 1996.

32. Roth P and Stanley E: The biology of CSF-1 and its receptor. Curr Top Microbiol Immunol 181: 141-167, 1992.

33. Chu CQ, Field M, Allard S, Abney E, Feldmann M and Maini RN: Detection of cytokines at the cartilage/pannus junction in patients with rheumatoid arthritis: implications for the role of cytokines in cartilage destruction and repair. Br J Rheumatol 31: 653-661, 1992.

34. Li J, Sarosi L and Yan XQ: RANK is the intrinsic hematopoietic cell surface receptor that controls osteoclastogenesis and regulation of bone mass and calcium metabolism. Proc Natl Acad Sci USA 97: 1566-1571, 2000.

35. Bord S, Ireland DC, Beavan SR and Compston JE: The effects of estrogen on osteoprotegerin, RANKL, and estrogen receptor expression in human osteoblasts. Bone 32: 136-141, 2003. 